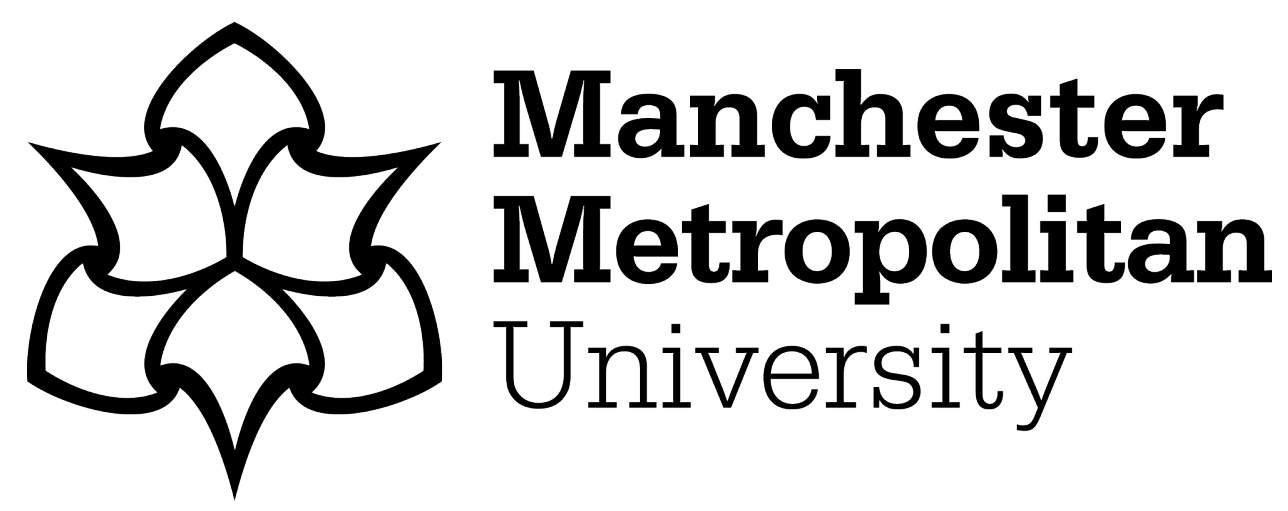

Moorhouse, Natasha, tom Dieck, Mandy ORCID logoORCID: https://orcid.org/0000-0002-8765-8969 and Jung, Timothy ORCID logoORCID: https://orcid.org/0000-0002-8594-6641 (2019) An Experiential View to Children Learning in Museums with Augmented Reality. Museum Management and Curatorship, 34 (4). pp. 402-418. ISSN 0964-7775

Downloaded from: https://e-space.mmu.ac.uk/622417/

Version: Accepted Version

Publisher: Taylor \& Francis (Routledge)

DOI: https://doi.org/10.1080/09647775.2019.1578991

Please cite the published version 
Accepted

Moorhouse, N., tom Dieck, M.C. \& Jung, T. (2019). Museum Management and Curatorship,

forthcoming.

\title{
An Experiential View to Children Learning in Museums with Augmented Reality
}

\begin{abstract}
Museums facilitate schoolchildren's experiential learning, and when combined with Augmented Reality (AR) applications, schoolchildren can benefit from interactive, engaging learning experiences. Experiential learning is therefore situated in a context relevant to schoolchildren's learning experience with digital technologies such as AR in museums, hence, it seems appropriate to employ Kolb's (1984) Experiential Learning Cycle as a theoretical base. A museum in the UK was used as a single case study, and experiments and three focus groups were conducted with 19 schoolchildren and data analysed using thematic analysis. This study revealed three new themes specific to schoolchildren's experiential learning experiences with AR in museums including: (1) integrating AR could further enhance knowledge acquisition, (2) schoolchildren were able to identify their preferred learning style, and (3) schoolchildren are motivated to continue learning with AR in museums. Theoretical contributions and practical implications are presented, as well as suggestions for future research.
\end{abstract}

Keywords: Augmented Reality; Experiential Learning Cycle; Learning Experience; Museum; Pupils

\section{Introduction}

Museums are ideal environments for facilitating children's experiential learning. Museum field trips are consistently integrated into many primary schools' curriculum because they are considered a powerful learning resource given their recreational and educational potential (Morentin and Guisasola 2014). Kolb's (1984) Experiential Learning Cycle is an influential experiential learning theory that has gained popularity in a variety of disciplines such as education, management, psychology, and computer and information science (Vince 1998, Petrovic et al. 2014). Studies have proven the cycle's validity in analysing young learners' experiences with digital technologies in a variety of contexts (e.g. Lai et al. 2009) including museums (e.g. Sung et al. 2010; Melber 2003). 
Studies noted the suitability of digital technologies, in particular mobile technologies, in facilitating experiential learning opportunities for children (Herrington and Herrington 2007; Lai et al. 2007, 2009; Sung et al. 2010). Implementing digital technologies in museum-based learning influences children's critical thinking in history, and evokes curiosity, memorable moments, discussions and explorations in exhibits in all museum types (Andre et al. 2017). Augmented Reality (AR) is a mobile technology that is receiving increasing attention from museum professionals, researchers, and educators because of its capacity to increase engagement and add value to the learning experience (Ding 2017). To date, research in this area is very limited and few studies have employed the Experiential Learning Cycle in this specific context. However, given the breadth of research supporting the cycle's cogency in similar studies, it seems appropriate to continue to investigate emergent technologies such as AR through the lens of the Experiential Learning Cycle. This study aims to explore AR's effectiveness in facilitating experiential learning experiences for schoolchildren in museums by employing Kolb's (1984) Experiential Learning Cycle as a theoretical base. More specifically, this study has two research objectives:

1) To examine the effectiveness of AR in facilitating schoolchildren's experiential learning in museums;

2) To contribute theoretically to experiential learning research by identifying emergent themes specific to schoolchildren's experiential learning experience with digital technologies such as AR in museum settings.

In doing so, this study provides a number of theoretical contributions and practical implications. Theoretically, employing Kolb's (1984) Experiential Learning Cycle in a new context allowed for the identification of context-specific factors for the application of $\mathrm{AR}$ in museum context. This contributes to experiential learning research in the museum context. In addition, limited studies have focused on schoolchildren's learning experience with AR, therefore, the present study, which focuses on schoolchildren, is an additional contribution to the literature in tourism and museum research. The key themes of experiential learning cycles including three emergent sub-themes provide important insights for the museum sector on the distinctive benefits of integrating innovative and interactive digital technologies such as AR to facilitate motivational and experiential learning environments for schoolchildren visiting museums. 


\section{Literature review}

\section{Children's Experiential Learning in Museums}

Children's learning takes place in a range of formal (e.g. traditional classroom) and informal environments (e.g. museums and other non-school-based environments) (Falk and Dierking 2000; Andre et al. 2017). Museums can be defined as informal learning environments providing various objects, exhibits, and programs developed around subjects of history, science, archaeology, and arts (Andre et al. 2017). Museum field trips offer excellent experiential learning activities and programs to develop schoolchildren's interest and are often integrated into many primary schools' curricula given their recreational and educational potential (Behrendt and Franklin 2014; Morentin and Guisasola 2014). Today's museum managers are striving to meet the needs of diverse visitors and are incorporating programs and strategies that acknowledge children as an important segment of society (McRainey and Russick 2010). This is not surprising given that children represent a significant proportion of museum visitor groups (Andre et al. 2017), and children aged 5-9 years are in the "critical age for converting children into lifelong museum-goers and advocates" (Centre for the Future of Museums 2008, 15). Indeed, many museum managers are committed to designing new exhibits and programs that target this audience (McRainey and Russick, 2010) and direct children's learning by providing unique opportunities to explore various subject concepts (Andre et al. 2017) including through the use of innovative media and Information and Communication Technologies (ICTs). Museums play an important role in facilitating lifelong learning, in terms of creative, cultural and intellectual activity beyond any merely vocational aspects (Hawkey 2004). Lifelong learning, museums, and digital technologies share many of the same attributes because they emphasise learning from objects, rather than about objects, and on strategies for discovering information, rather than the information itself (Hawkey 2004). Engaging in experiences through movement and senses is an essential part of children's learning and development, however children must also be willing to participate in active learning and able to create and think critically (Stewart 2014; Eh Phon and Ali 2014).

To be an effective learner requires involvement, concentration, expended effort, and perseverance with challenging activities (Stewart 2014). This method of learning is 
referred to as 'experiential learning', however, other common descriptors for the approaches in education are 'authentic', 'learner centred', and 'active' (Dyson et al. 2009). In this study, the term 'experiential learning' has been adopted and can be defined as learning that results from the learner's own experience of action in the real world, reflection on this experience that leads to abstract conceptualisation, followed by experimentation with the new concepts formed (Kolb 1984). Experiential learning differs from the idealist approaches of traditional education and from the behaviour theories (e.g. Watson, Hull, Skinner) because it emphasises the process of learning rather than the outcome of learning (Kolb, 1984). Experiential activities involve exploration, touching, listening, watching, moving, and dissembling and reassembling things (Behrendt and Franklin 2014). Experiential learning emphasises the role that appropriate places and experiences play in the learning process (Lai et al. 2009), and it has been found to increase schoolchildren's interest, knowledge, and motivation in both formal and informal field trip venues (Behrendt and Franklin 2014). Experiential learning is linked with theories of constructivism that introduce the belief that learning is an internal process that is influenced by genetics and environment, and young children construct knowledge by integrating experiences through a process of assimilation and accommodation, building and refining concepts as new information is required (McRainey and Russick 2010; Yardley et al. 2012). It is commonly accepted that concrete, sensory-based experiences offer a foundation for developing more abstract understandings, and that beginning with simple ideas allows for the eventual exploration of more complex concepts (McRainey and Russick 2010).

Previous museum research has largely focused on children visiting museum exhibits (Hooper-Greenhill and Moussouri 2000), and more recent research tends to describe children's learning through participation in programs or workshops, or through the use of educational materials (e.g. media and technologies) and objects (Andre 2017). However, further research is required into children's experiences and perceptions of their museum encounters, including technology-enhanced experiences, in order to inform museum communities about the experiential aspects that children find most rewarding, as this would assist in the developmental aspects of exhibitions and programs which have educational and experiential impact for young visitors (Piscitelli and Anderson 2015). 


\section{Children Experiential Learning with Augmented Reality in Museums}

In recent years, digital technologies such as web-based services (e.g. Parry 2013; Marty 2007), ubiquitous learning applications (e.g. Shih et al. 2011; Chu et al. 2010; Lin and Lan 2012), game-based learning programmes (e.g. Hong et al. 2013), mobile learning applications (Vavoula et al.2009), and more recently AR applications (e.g. Chiang et al. 2014; Kamarainen et al. 2013) have been increasingly used in museums to enhance children's learning experiences (Hsu and Liang 2017). Digital technologies can support learners in authentic and seamless learning and allow learning to be held at any time and place (Lai et al. 2007; Lai et al. 2009). Researchers have investigated the use of digital technologies to facilitate experiential learning experiences more generally (e.g. Lai et al. 2007; Lai et al. 2009; Herrington and Herrington 2007) and in the context of children's experiential learning in museums (e.g. Melber 2003; Sung et al. 2010). Studies have indicated that mobile technologies increase interest and facilitate inquiry activities in the museum such as exploration, information search, communication, and experience documenting (Hsi 2002; Curtis et al. 2002; Ogata and Yano 2004; Sung et al. 2010; Herrington and Herrington 2007; Lai et al. 2007, 2009). According to Herrington and Herrington (2007), mobile technologies are suited to experiential learning because they provide a tool for complex and sustained tasks and problem solving. Lai et al's. (2007, 2009) studies demonstrate the advantage of using mobile technologies for improving knowledge creation, knowledge acquisition, enhancing awareness of learning in context, and further highlight the importance of mobile technologies in improving the learning achievement of experiential learning (Lai et al. 2007, 2009). Further studies indicate that mobile technologies can make learning expedient, immediate, authentic, accessible, efficient, and convenient (Curtis et al. 2002; Ogata and Yano 2004).

Technology can become a facilitator of interactions and connections between all involved actors, can enhance enjoyment and the effectiveness of learning, and increase engagement in other activities in the museum environment (Piccialli and Chianese 2017; Andre et al. 2017). However, in order to bridge the gap between the museum's heritage offerings and visitor expectations, it is important for the technology to engage visitors, increase their interest, and combine factors including availability, accessibility, and usefulness to offer opportunity for visitor participation (Hassan \& Ramkissoon, 2016). Museum exhibitions that are supported with technology integration and activities can positively influence 
children's critical thinking skills in history, and evoke curiosity, excitement, memorable moments, discussions and explorations during exhibits (Andre et al. 2017). Therefore, mobile applications have become widely used in museums on a global scale, and some museums are beginning to explore ways to weave in more interactive and customised features to enhance the museum experience (Ding 2017). Implementing digital technologies in museum-based learning has changed learning by combining physical and virtual worlds (Hsu and Liang 2017). Indeed, there is increasing interest from museum curators and visitors at several destinations in the application of AR technology in museums, which facilitates both technology development and practical use (Hassan \& Ramkissoon, 2016). Prior studies have indicated that AR can help attract various visitor segments (Hassan \& Ramkissoon 2016) including young children (Cianciarulo 2015). For instance, Cianciarulo (2015) found that museums offering AR experiences build on the individual's curiosity in trying the new technology, with people visiting the museum specifically to try AR and thereby increasing visitor numbers. In this study, the ARenhanced museum experience was particularly enjoyed by young children (Cianciarulo 2015). AR converges with mobile technology and has become a portable tool for discovery-based learning that can enhance the available information in gallery spaces, and interactions and engagement with real-world objects and exhibitions (Ding 2017; Angelopoulou et al. 2012). However, AR is unique in that it can impose layers of virtual content including 3D digital models and 2D graphics, text, audio, and video on top of real-world objects and artefacts, providing access to normally hidden data that individuals can use to develop deeper knowledge about a content area (Yoon et al. 2014; Tesoriero et al. 2014). People have become accustomed to handling mobile devices, and thus, scanning an AR object with the mobile device is easily implemented into the museum experience (Ding 2017). AR allows people to obtain knowledge of the displayed objects and artefacts in an interactive and informative way and is therefore considered a powerful tool for engagement and a creative tool for education (Ding 2017). Interactivity is increasingly seen as essential to children's museum learning experiences and is a key feature of AR learning applications because it can assist with making connections between museum artefacts and images and visitors lives and memories (Andre et al. 2017; Sungkur et al. 2012; Bedford 2001). In addition, AR could stimulate learning motivation and achievement, and enhance the flexibility and interactivity of learning activities (Lee et al. 2011). For example, children could enjoy a sense of accomplishment when they succeed at using the AR application and their imaginations and curiosities could expand 
when using the AR features, thereby adding value to children's learning in museums and encouraging experiential learning (Ding 2017).

\section{Kolb's Experiential Learning Cycle}

Numerous experiential learning theories (e.g. Dewey 1938; Kolb 1984; Knowles 1980), originating from different philosophical views of the nature of knowledge have been proposed (Yardley et al. 2012). However, Kolb's Experiential Learning theory (1984) remains very influential and has gained much popularity in the discourse of learning theories (see figure 1) (Vince 1998, Petrovic et al. 2014). Experiential learning is routinely applied in a variety of scopes and research areas including education, management, computer and information science, psychology, medicine, nursing, accounting, and law (Kolb 2000). The experiential learning cycle draws on several characteristics found in the earlier learning models of Lewin (1939), Dewey (1938), and Piaget (1970), and consists of several characteristics. The characteristics include: 1) learning is best conceived as a process, not in terms of outcomes, 2) learning is a continuous process grounded in experience, 3 ) learning is a holistic process of adaptation to the world, 4) learning involves transactions between the person and the environment, and 5) learning is the process of creating knowledge. Studies have adopted the model to explore experiential learning with digital technologies (e.g. Lai et al. 2009; Lai et al. 2007; Day and Verhaart 2015) because it provides a learning framework and holistic process to design interactive learning experiences (Bolan 2003). By employing the experiential learning cycle as a theoretical base, Lai et al. (2007) found that mobile technologies are effective in improving knowledge creation during experiential learning. Later, Lai et al. (2009) were able to demonstrate the importance of mobile learning in helping to improve the learning achievement of experiential learning and confirmed that using mobile technologies is advantageous for the acquisition of knowledge. In addition, Day and Verhaart (2015) found that a combination of web-based and mobile technologies successfully support field-based learning for undergraduate students. AR is an emergent technology that has received increasing interest in recent years. Therefore, there are many areas requiring further research including the application of the Experiential Learning Cycle in the context of schoolchildren learning with AR in museum settings. 


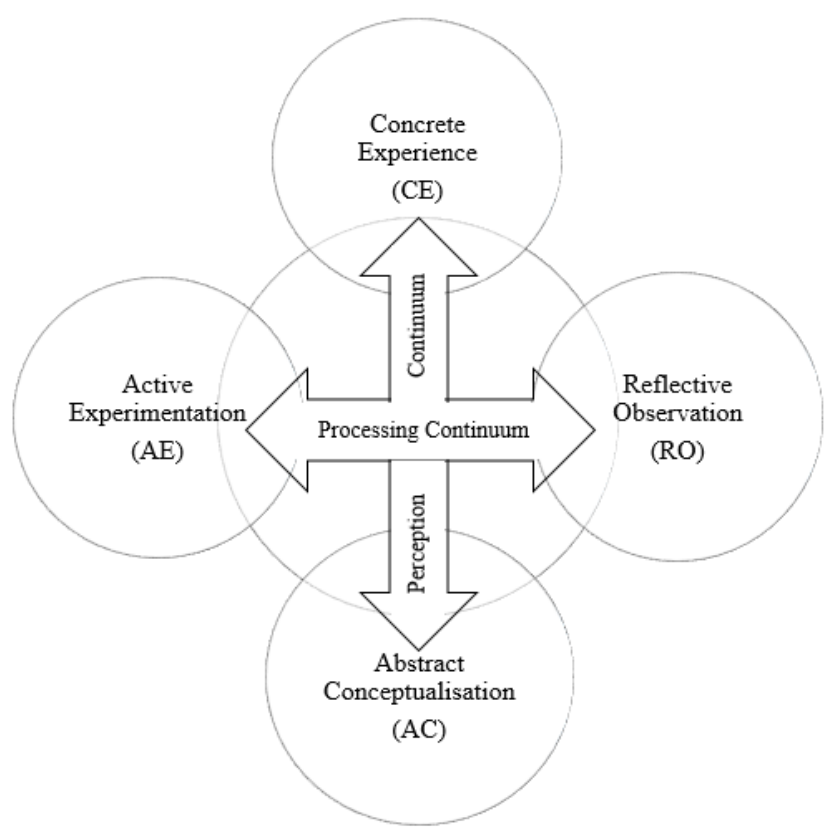

Figure 1. The Experiential Learning Cycle (Kolb, 1984)

According to Kolb (1984), if learners are to be effective they need four different kinds of abilities including concrete experience (CE) abilities, reflective observation (RO) abilities, abstract conceptualisation (AC) abilities, and active experimentation (AE) abilities. The experiential learning cycle assumes that learners begin with a concrete experience, upon which they develop observations and reflections, and from this reflective observation, learners construct abstract concepts that can guide future actions (Lai et al. 2007). Once those concepts have been developed, learners actively test their constructs, which leads to new experiences and renews the learning cycle (Barker et al. 2002), hence the continuous cycle portrays learning as an on-going lifelong process (Kolb 1984). However, Kolb (1984) pointed out that learning requires abilities that are polar opposites, and as a result, the learner must continually choose which set of learning abilities he or she will bring to any specific learning situation. Therefore, there are two primary dimensions to the learning process, whereby the first dimension represents the concrete experiencing of events at one end and abstract conceptualisation at the other, and the other dimension has active experimentation and reflective observation at either end (Kolb 1984). In other words, during the process of learning one moves in varying degrees from actor to observer, and from specific involvement to general analytic detachment (Kolb 1984). Further, the horizontal axis represents a processing continuum on how people approach a task (active experimentation and reflective observation), and the vertical axis is a perception continuum on how people feel about said task (concrete 
experience and abstract conceptualisation). The experiential learning cycle has been employed as a theoretical base for this study as it is useful in identifying new learning opportunities than traditional learning methods and portrays experience as central to the learning process. AR is a relatively new learning tool for schoolchildren's experiential learning in museums, which encourages them to actively explore the museum environment. Although the cycle remains a popular learning theory, there are limited studies applying the learning cycle in the context of schoolchildren's experiential learning experience with $\mathrm{AR}$ in museums. Indeed, given the experiential nature of museum experiences facilitated by AR applications, this cycle is considered appropriate for this study.

\section{Method}

\section{Study Context}

Two research objectives were established including: (1) to examine AR's effectiveness in facilitating schoolchildren's experiential learning in museums, and (2) to contribute theoretically to experiential learning research by identifying emergent themes specific to schoolchildren's experiential learning experience with digital technologies such as AR in museum settings. A new AR application was developed specific to the museum used as a single case study and installed on several iPads provided by the museum. An exploratory qualitative approach was taken with an aim to explore AR's effectiveness as an experiential learning tool in this specific context. The following sections describe the details of the methodology design used in the experiment.

\section{Study Design}

A single case study was used focussing on a museum in the UK. Experiments and focus groups were conducted with one class of 19 schoolchildren aged 7-8 years from one local school. This group of schoolchildren often visit the museum as part of their curriculum of cultural studies. Therefore, given the existing relationship between the school, the teacher, the schoolchildren, and the museum, the museum manager invited the teacher and class to participate in this research study. In liaison with the teacher of the class, it was possible to obtain informed consent from each of the schoolchildren's parents prior to the study being conducted. Then, the museum manager assisted with coordinating a suitable date and time between the school and researchers to conduct the focus groups. 
To begin the experiment, the schoolchildren were allocated approximately 30 minutes to explore the museum and identify several points of interest through the AR application. Then, the schoolchildren had a first attempt at completing the quiz on the application while participant observation was conducted. Directly afterwards, the schoolchildren were divided into groups of 6-7 and three focus groups were conducted on the museum premises.

\section{Data Collection}

The focus groups were conducted during one day at the museum in June 2016. Each focus group lasted approximately 20 minutes, and questions were mapped to the four dimensions of Kolb's (1984) Experiential Learning Cycle: 1) concrete experience, 2) reflective observation, 3) abstract conceptualisation, and 4) active experimentation). To begin, the schoolchildren completed the quiz a second time to assess the new knowledge and skills gained from the AR application. Following questions included, 'Did you enjoy using the AR application at the museum today?' (concrete experience), and, 'Tell me what you liked about using the AR application at the museum today' (reflective observation). Given the age of the schoolchildren, it seemed to appropriate to tailor several questions into interactive activities to encourage participation and increase engagement in the focus group. For example, one activity allowed the schoolchildren to identify and match up printed cards of the images and answers drawn from the interactive quiz that were identifiable through the AR feature. The aim of this activity was to explore the new knowledge and skills gained from the AR experience (abstract conceptualisation). Final questions aimed to investigate schoolchildren's future intentions and desire to use the AR application at the present museum and similar cultural heritage sites (active experimentation).

\section{Data Analysis}

Data were analysed using thematic analysis, which is a "method for systematically identifying, organising, and offering insight into, patterns of meaning (themes) across a data set" (Braun and Clarke 2012, 58). Thematic analysis is one of the most common qualitative data analysis techniques (Guest et al. 2011) and given the exploratory nature of the qualitative focus group approach, this method was considered most appropriate to align previously identified themes drawn from the literature and investigate new themes emerging from the focus groups. The schoolchildren were coded from P1-P19. To begin the analysis, focus group transcriptions were input into NVivo for analysis. Then, the data 
were coded in accordance to the four main components of the experiential learning cycle 1) concrete experience, 2) reflective observation, 3) abstract conceptualisation, and 4) active experimentation. In reviewing the data under each overarching theme, two subthemes for each main theme emerged as presented in Table 1 in accordance to the Experiential Learning Cycle.

\section{Findings}

This study evaluates the effectiveness of the AR application as an experiential learning tool for schoolchildren in museums. Several introductory questions explored the schoolchildren's overall perceptions towards the AR application as an experiential learning tool in the museum. The overall view with regards to using the AR application for this purpose was that it provided the schoolchildren with an interactive learning tool by engaging them in a new experience where they could learn new knowledge from that experience. Engaging with the application encouraged the schoolchildren to actively explore the museum environment and engage with the objects and artefacts in novel ways. Furthermore, the following subsections describe the themes and sub-themes that confirm previous studies findings including increased engagement with the learning environment, evoked curiosity, personal achievement, and motivation to continue learning with AR. More importantly, this study contributes three new sub-themes including increased interactivity, new knowledge acquisition, and identification of preferred learning style.

Table 1. Themes \& Sub-themes 


\begin{tabular}{|l|cc|}
\hline Concrete & $\bullet$ & Novel learning experiences \\
Experience & $\bullet$ & Increased engagement with the learning \\
& & environment \\
\hline Reflective & $\bullet$ & Increased interactivity \\
Observation & $\bullet$ & Evoked curiosity \\
\hline Constract & $\bullet$ & New knowledge acquisition \\
\hline Active & $\bullet$ & Personal achievement \\
Experimentation & $\bullet$ & Preferred learning style \\
& $\bullet$ & AR learning motivation \\
\hline
\end{tabular}

\section{Information on Participants}

The schoolchildren were aged between 7 and 9 years old and in primary school years 3 and 4. The focus groups consisted of mixed groups in terms of demographic profile (age, gender, and respective school year).

\section{Concrete Experience}

Concrete experience refers to a new experience or a reinterpretation of an existing experience. In this study, the new experience refers to the schoolchildren using the AR application for experiential learning in the museum. As previously mentioned, the schoolchildren had visited the museum prior to this research study as part of the school's curriculum, however, they had not used iPads or AR technology to facilitate the learning experience at the museum. Indeed, this was advantageous because it allowed the schoolchildren to compare the previous museum experience with the AR-enhanced museum experience.

\section{Novel learning experiences}

When comparing the experiences with and without AR technology, the majority of schoolchildren perceived the AR-enhanced museum experience more positively than the prior experiences. This is because the AR application presented novel ways to experience 
and learn about the museum's objects and artefacts, which made the overall visit more enjoyable and exciting than previous visits. For instance, P8 stated, "the people on the app made the experience more fun". Moreover, the schoolchildren stated that the AR application enabled them to uncover new information and stories behind the objects and artefacts. This is evident because when the schoolchildren were asked whether they would have learned the new facts without using the AR application, P2 responded "no, the app helped because there was no information available otherwise", and P10 stated "the app helped because there were hidden stories that we discovered when we were scanning".

\section{Increased engagement with the learning environment}

Each of the schoolchildren expressed enjoyment in learning outside the usual classroom environment and in the museum environment (i.e. the synagogue). More importantly, the AR application encouraged them to explore the environment in new ways, and actively engage with the objects and artefacts as P7 stated, "I enjoyed going up to the Bimah because when we scanned [the QR code] I liked it because the 2D man came up and told us all about it...the 2D man kept me interested". In addition, the schoolchildren (P1-P19) were motivated to explore the environment with peers rather than the teacher because they felt in control of their own learning experience.

\section{Reflective Observation}

Reflective observation refers to the learner reflecting on the new experience. Prior to answering the focus group questions, the schoolchildren were allocated time to reflect on the AR experience in pairs. The following questions explored the most and least enjoyable aspects of using the AR application to learn in the museum.

\section{Increased interactivity}

Interactivity increased through the AR graphics including the $2 \mathrm{D}$ and $3 \mathrm{D}$ avatars, text, images, and audio. This is evident as the 2D and 3D graphics superimposed over the real objects were favoured by several schoolchildren (P1, P4, P6, P7, P11, P13, P14, P15, P16, P19). In support of this, P15 stated, "I enjoyed the virtual experience where we got to see and hear about what happened in the past in the museum". Moreover, the 2D and $3 \mathrm{D}$ avatars increased interactive engagement, and listening to the audio combined with 
the avatars was preferred by P1, P15, P16, and P19. In support of this, P1 stated, "I enjoyed when the [3D] man sung a song" and P19 stated, "I enjoyed the virtual experience where we got to see and hear about what happened in the past in the museum". When asked questions about the knowledge acquired from the AR experience, the schoolchildren could reiterate information that was provided mainly through the $2 \mathrm{D}$ and 3D avatars. For instance, P3, "[learned] that chair 87 was were someone very important used to sit and that is why we had to scan it". This indicated that the majority of new knowledge acquired was from using the AR application as a learning tool.

\section{Evoked curiosity}

Uncovering the hidden information about the museum objects and artefacts evoked the schoolchildren's curiosity in learning about the history of the museum. This is evident as P1 stated "I learned that there were four lions. At first, I thought there was three, but I went to check again and there was actually four", and P3 "we learned that the synagogue is where the people sit, and I did not know that". This implies evoked curiosity and a desire to learn and reveal the hidden information about the objects and artefacts displayed in the museum. To further support this, P14 stated "I really liked scanning the codes because it told us information about the past", and P19 requested "more options to explore the museum, because there is only one option to read about the museum and I thought there could be a few more".

\section{Abstract Conceptualisation}

Abstract conceptualisation follows reflective observation because it involves the abstract concepts that are drawn from reflecting on the experience that could guide future actions. During the focus groups, abstract conceptualisation explored the response to using the quiz to learn about the museum following the AR experience, and assessed the new knowledge acquired from the AR experience. By advancing knowledge in this topic area, this could compliment the schoolchildren's educational success in cultural studies which is embedded in the school's curriculum. 
P10 and P16 thoroughly enjoyed the quiz because they were able to assess the level of knowledge acquired as a result of using the AR application as a learning tool, as P10 stated, "I liked the quiz because then you get to know how much you have learned about the Jewish religion". However, completion of the quiz post-AR-experience was considered too challenging for several schoolchildren (P1, P4-P9, P11, P13, P14). Hence, P6 suggested completing the quiz while exploring the museum with the AR application "and then test us again at the end", which indicates the need to tailor the AR experience and implement the quiz pre-experience or post-experience depending on the personal ability and age group of schoolchildren. Moreover, P4 stated, "my favourite was when we scanned, and it told us different languages that they spoke...I enjoyed learning and hearing about the different languages", thus, highlighting the extensive ways AR applications could be implemented to provide schoolchildren with new knowledge and skills in this specific context.

\section{Personal achievement}

Several schoolchildren enjoyed the challenge of locating the points of interest (P2, P6, P7, P12, P16) and testing the new knowledge acquired through the quiz (P2, P10, P12, P16) as both led to feelings of personal achievement. In support of this, P10 stated, "I enjoyed the quiz because then I felt like I had learned something new", and P16 was driven to complete additional quizzes and requested "you could add more quizzes because it is nice for adding more fun". Moreover, P6 stated "I really enjoyed learning new things about the Jewish religion and the synagogue", and P7 stated, "I liked when you go up to the [Bimah], when we scanned and the [2D] man came up, I enjoyed it because he told us about [the Bimah]".

\section{Active Experimentation}

Active experimentation refers to the learner applying the new knowledge to the real world to assess the results of the knowledge gained from the experience. In this study, active experimentation explored the schoolchildren's intention and desirability to use an AR application to learn in other museums. 


\section{Preferred learning style}

The diversity of graphics integrated into the AR application encouraged the schoolchildren to express their individual preferred learning style whether that be kinaesthetic (physical), linguistic (verbal), spatial (visual), or aural (auditory-musical). This became evident from several recommendations for improvements, such as P14 who stated, "if there was also text on the screen [with the 2D/3D avatars], then I could learn to read the words and speak them correctly...the text and sound together are helpful in teaching me how to pronounce words correctly". This was echoed by P18, "I think that when the picture comes up it should have text with the talking animation...because I prefer to read as well...it was too difficult to just listen because the animation speaks so fast".

\section{AR learning motivation}

Overall, P1-P19 confirmed that they are motivated to re-visit the museum specifically to experience the AR application again, and P4 expressed interest in downloading the application on a personal device to repeat the experience outside of school hours ("can I download the app on my phone so I can use it again?"), which indicates a thorough enjoyment and intention to repeat the AR experience. In addition, P1-P19 confirmed they would be more inclined to visit other cultural heritage sites that provide similar AR learning experiences compared with those that are yet to implement AR technologies. During the focus groups, the schoolchildren completed the quiz for a second time in pairs, and each pair achieved more correct answers than the first quiz attempt. The schoolchildren were motivated to use AR to learn again because it was "fun" and "I learnt new things" (P10, P15), and requested "more options for us to explore the museum...there is only one option to read about the museum and I thought there could be a few more" (P15).

\section{Discussion and Conclusion}

The present study aimed to contribute to the literature on schoolchildren's experiential learning experiences with digital technologies in museums. Kolb's Experiential Learning Cycle (1984) provided a useful conceptual base to analyse schoolchildren's response towards using the AR museum application to facilitate experiential learning experiences in this specific context, thus supporting its suitability to learning in museums with 
emergent technologies research. By employing the cycle in this new context, several subthemes, including three new themes, emerged from the data set in accordance to the four dimensions of the Experiential Learning Cycle. From experiencing the diverse range of media within the AR museum application, the schoolchildren were able to identify the learning style most effective for them. This is particularly important considering the target group, as this could be useful for them to guide future actions (Lai et al. 2007; Kolb 1984) and could provide useful information for developers and museum managers when considering the design and development of future AR museum applications. The latter is important given that recent research (He et al. 2018) has begun to investigate the influential effects of AR design elements (e.g. dynamic verbal cues and dynamic visual cues) on visitors' behaviour in museum tourism. However, this study presses the need for further research focusing specifically on the design elements of AR for schoolchildren's museum learning experience. Moreover, this study supports previously identified benefits of using mobile technologies to learn in museums. For instance, although previous studies (e.g. Lai et al. 2007, Lai et al. 2009; Ding 2017) have indicated the benefits of mobile technologies including knowledge creation and knowledge acquisition, this study illustrates how integrating an AR function could further enhance those benefits for schoolchildren's experiential learning experience. This study also provides supporting evidence that AR has the potential to provide novel and authentic museum learning experiences, which are attractive for schoolchildren (Lai et al. 2007; Lai et al. 2009; Cianciarulo 2015), stimulate learning motivation and achievement (Lee et al. 2011), and further adds that such benefits translate into the schoolchildren's desire to visit other museums utilising AR. The schoolchildren's engagement with the museum environment and curiosity to learn more about the museums historical objects and artefacts increased because of using the AR application (Piccialli and Chianese 2017; Andre et al. 2017). The findings highlight the importance of generating stimulating and interactive museum experiences (Andre et al. 2017; Sungkur et al. 2012), which can be achieved through the use of AR graphics. However, given AR's unique feature to superimpose such graphics over real-world objects (Yoon et al. 2014; Tesoriero et al. 2014), this distinguishes it from other forms of digital technologies.

\section{Theoretical Contribution}

This study offers a number of theoretical contributions. Limited studies have employed Kolb's Experiential Learning Cycle (1984) as a theoretical base to investigate AR as a 
learning tool for schoolchildren in museums. The findings contribute to extensive knowledge on experiential learning and using AR to facilitate learning in museums. To date, there is limited research investigating children's learning and engagement with AR as part of the museum experience. Previous research (e.g. tom Dieck et al. 2016) explored AR's capabilities from a lifelong learning perspective, however, a focus on children is an important contribution within museum and tourism research. The three themes identified specific to AR include (1) the motivation to continue learning with AR, (2) schoolchildren were able to identify their preferred learning style by experiencing the AR application, and (3) integrating an AR function into mobile applications could further enhance knowledge acquisition. Finally, using the Experiential Learning Cycle as a theoretical foundation, this study contributed to its research by identifying context-specific subthemes for the AR museum context.

\section{Practical Implications}

There are several implications for the culture heritage sector in general and the museum sector in particular. This study provides empirical evidence for museums and other cultural heritage sites on the power of AR in facilitating experiential learning opportunities for children. Considering the increased importance of learning as part of the museum experience, this study provided evidence as to how AR can be used in order to create novel, interactive and highly motivational learning environments. Museum curators, tourism practitioners, and application developers can utilise these findings to create useful AR learning scenarios that are sympathetically integrated into the museum experience. Finally, findings provide implications for exhibition design when targeting the younger audience as AR provides an interesting opportunity to capture interest, enhance motivation to learn and provide a reason to return to museums.

\section{Limitations and Future Research}

Although the AR application was effective in facilitating the schoolchildren's experiential learning experience in the museum, this study has a number of limitations that need to be considered in the future. The first limitation relates to the study design and a single case study approach. The sample was limited to 19 schoolchildren which limits the generalisability of the findings. As the study was conducted employing only one museum in the UK, similar studies adopting this approach underpinned by the experiential learning cycle in this specific context are required for comparison of the 
findings. Given that this study uses a limited sample of schoolchildren in a specific age category, future studies using a diverse sample (e.g. children at varying age groups and cognitive ability) would strengthen the research surrounding the effectiveness of digital technologies such as AR in enhancing children's experiential learning in museums. Finally, research relating to AR application requirements for various learning capabilities are required, to allow developers and researchers to configure AR applications that are capable of effectively facilitating experiential learning for schoolchildren of all ages in museums.

\section{References}

Andre, L., T. Durksen, M.L. Volman. 2017. "Museums as avenues of learning for children: a decade of research." Learning Environment Research 20: 47-76.

Angelopoulou, A., D. Economou, V. Bouki, A. Psarrou, L. Jin, C. Pritchard, C. and F. Kolyda. 2012. "Mobile augmented reality for cultural heritage." Mobile Wireless Middleware, Operating Systems, and Applications. Institute for Computer Sciences, Social Informatics and Telecommunications Engineering 93: 15-22.

Barker, A.C., P.J. Jensen, D.A. and Kolb. 2002. Conversational Learning: An approach to knowledge creation. Westport, CT: Quorum.

Bedford, L. 2001. "Storytelling: The real work of museums." Curator: The Museum Journal, 44(1): 27-34.

Behrendt, M. and T. Franklin. 2014. "A review of research on school field trips and their value in education." International Journal of Environmental and Science Education 9: 235-245.

Bolan, C. 2003. "Incorporating the experiential learning theory into the instructional design of online course." Nurse Educator 28(1): 10-14.

Braun, V. and V. Clarke. 2012. "Thematic analysis." In APA Handbook of Research Methods in Psychology, 2, Research Designs: Quantitative, qualitative, neuropsychological, and biological, edited by H. Cooper, P. M. Camic, D. L. Long, A. T. Panter, D. Rindskopf, and K. J. Sher, 57-71. Washington, DC: American Psychological Association.

Centre for the Future of Museums. 2008. "Museum and Society 2034: Trends and Potential Future." Prepared for the American Association for Museums by Reach Advisors. www.futureofmuseums.org/reading/publications 
Cianciarulo, D. 2015. From local traditions to "Augmented Reality". The MUVIG Museum of Viggiano (Italy). Procedia Social and Behavioural Science, 188: 138143.

Chiang, T.H.C., S.J.H. Yang and G.J. Hwang. 2014. “An augmented reality-based mobile learning system to improve students' learning achievements and motivations in natural science inquiry activities." Educational Technology and Society, 17(4): $352-365$.

Chu, H.C., G.J. Hwang and J.C. Tsend. 2010. "An innovative approach for learning and employing electronic libraries to support context-aware ubiquitous learning." The Electronic Library, 28(6): 873-890.

Curtis, M., K. Luchini, W. Bobrowsky, C. Quintana and E. Soloway. 2002. "Handheld use in K-12: A descriptive account. In Proceedings of IEEE International Workshop on Wireless and Mobile Technologies in Education (WMTE), 23-30. IEEE Computer Society Press, Los Alamitos, CA.

Day, S. and M. Verhaart. 2015. "Integrating cloud and mobile technologies in experiential learning: From reality to reflection." $6^{\text {th }}$ Annual Conference of CITRENZ2015, 16.

Dewey, J. 1938. Experience and education, New York: Collier Books.

Ding, M. 2017. “Augmented reality in museums." Arts Management and Technology Laboratory: 1-12.

Dyson, L.E., A. Litchfield, E. Lawrence, R. Raban and P. Leijdekkers. 2009. “Advancing the m-learning research agenda for active, experiential learning: Four case studies." Educational Technology, 25(2): 250-267.

Eh Phon, D.N. and M.B. Ali. 2014. "Collaborative augmented reality in education: A review." In Proceedings - 2014 International Conference on Teaching and Learning in Computing and Engineering, Latice 2014: 78-83.

Falk, J.H. and L.D. Dierking. 2000. Learning from museums: Visitors experiences and the making of meaning, Walnut Creek, CA: AltaMira Press.

Guest, G., K.M. MacQueen and E.E. Namey. 2011. Applied thematic analysis, Thousand Oaks California, Sage.

Hassan, A., and Ramkissoon, H. 2016. "Augmented reality application to museum visitor experiences." Visitor Management in Tourist Destinations, CABI, Wallingford, $\mathrm{UK}: 117-130$. 
Hawkey, R. 2004. "Learning with digital technologies in museums, science centres and galleries." Future Lab Series: 1-40.

He, Z., Wu, L., \& Li, X. 2018. "When art meets tech: The role of augmented reality in enhancing museum experiences and purchase intentions." Tourism Management, 68: 127-139.

Henderson, T.Z. and D.J. Atencio. 2007. "Integration of play, learning, and experience: What museums afford young visitors." Early Childhood Education, 35: 245-251.

Herrington, A. and J. Herrington. 2007. "Authentic mobile learning in higher education." Paper presented at Australian Association for Research in Education (AARE) 2007 Conference: 1-9.

Hooper-Greenhill, E. and T. Moussouri. 2000. Researching learning in museums and galleries 1990-1999: A bibliographic review, Leicester: Research Centre for Museums and Galleries.

Hong, J.C. Hwang, M.T. Chen, Y.J. Lin, P.H. Huang, Y.T. Cheng, H.Y. and Lee, C.C. 2013. "Using the saliency-based model to design a digital archaeological game to motivate players' intention to visit the digital archives of Taiwan's natural science museum." Computers \& Education, 66: 74-82.

Hsi, S. 2003. "The electronic guidebook: A study of user experiences mediated by nomadic web content in a museum setting." International Journal of ComputerAssisted Learning, 19: 308-319.

Hsu, T.Y. and H.Y. Liang. 2017. “A cyclical learning model to promote children's online and on-site museum learning." The Electronic Library, 35(2): 333-347.

Kamarainen, A.M. Metcalf, S. Grotzer, T. Browne, A. Mazzuca, D. Tutwiler, M.S. and Dede, C. 2013. "EcoMOBILE: Integrating augmented reality and probeware with environmental education field trips." Computers \& Education, 68: 545-556.

Kolb, D.A. 1984. Experiential Learning: Experience as the source of learning and development, New Jersey: Pearson Education.

Kolb, D. 2000. "Learning places: Building dwelling thinking online". Journal of Philosophy of Education, 34(1): 121-133.

Knowles, M.S. 1980. The modern practice of adult education: From pedagogy and andragogy, 2, San Francisco, CA: Jossey-Bass.

Lai, C.H., J.C. Yang, C.F. Chen, C.W. Ho and W.T. Chan. 2007. "Affordances of mobile technologies for experiential learning: the interplay of technology and pedagogical practices." Journal of Computer Assisted Learning, 23: 326-337. 
Lai, C.H., J.C. Yang, C.F. Chen, C.W. Ho, W.T. Chan and J.S. Liang. 2009. "Mobile technology supported experiential learning." International Journal of Instructional Media, 36(1): 41-54.

Lee, H., M. Billinghurst and W. Woo. 2011. "Two-handed tangible interaction techniques for composing augmented blocks." Virtual Reality, 15(2): 133-146.

Lewin, K. 1939. "Field theory and experiment in social psychology: Concepts and methods." American Journal of Sociology, 44(6): 868-896.

Lin, H.T. and L.W. Lan. 2012. "An exhibition guiding system with enhanced interactive functions." The Electronic Library, 30(1): 120-133.

Marty, P.F. 2007. "Museum websites and museum visitors: before and after museum visit." Museum Management and Curatorship, 22(4): 337-360.

Melber, L.M. 2003. "Partnerships in science learning: Museum outreach and elementary gifted education." Gifted Child Quarterly, 47(4): 251-258.

McRainey, D.L. and J. Russick. 2010. Connecting kids to history with museum exhibitions, Routledge.

Morentin, M. and J. Guisasola. 2014. "The role of science museum field trips in the primary teacher preparation.” International Journal of Science and Mathematics Education, 13(5): 965-990.

Ogata, H. and Y. Yano. 2004. "Context-aware support for computer-supported ubiquitous learning." In Proceedings of IEEE International Workshop on Wireless and Mobile Technologies in Education (WMTE). 27-34. IEEE Computer Society Press, Los Alamitos, CA.

Parry, R. 2013. Museums in a Digital Age, Routledge, New York, NY.

Petrovic, O., P. Babcicky and T. Puchleitner. 2014. "An environment for mobile experiential learning." Paper presented at the $10^{\text {th }}$ International Conference on Mobile Learning, 271-276.

Piaget, J. 1970. Main trends in psychology. London: George Allen \& Unwin.

Piscitelli, D. and Anderson, D. 2015. "Young children's perspectives of museum settings and experiences." Museum Management and Curatorship, 19(3): 269-282.

Piccialli, F. and Chianese, A. 2017. "Cultural heritage and new technologies: Trends and challenges." Personal and Ubiquitous Computing, 21: 187-189.

Radu, I. 2014. "Augmented reality in education: A meta-review and cross-media analysis." Personal and Ubiquitous Computing, 18: 1533-1534. 
Ramkissoon, H. and Uysal, M. S. 2014. Authenticity as a value co-creator of tourism experiences, in Creating Experience Value in Tourism. In Prebensen, N. K., Chen, J. S. and Uysal, M.S. (eds.) Creating Experience Value in Tourism, CABI, Wallingford, UK, pp. $113-124$.

Shih, J.L., G.J. Hwang, Y.C. Chu and C.W. Chuang. 2011. "An investigation-based learning model for using digital libraries to support mobile learning activities." The Electronic Library, 29(4): 488-505.

Stewart, N. 2014. Active Learning. In H. Moylett (Ed). Characteristics of effective early learning: helping young children become learners for life. Maidenhead: Open University Press.

Sungkur, R.K., A. Panchoo and N.K. Bhoyroo. 2016. "Augmented reality, the future of contextual mobile learning." Interactive Technology and Smart Education, 13(2): 123-146.

Sung, Y., H. Hou, C. Liu and K.E. Chang. 2010. "Mobile guide system using problemsolving strategy for museum learning: A sequential learning behavioural pattern analysis." Journal of Computer Assisted Learning, 26(2): 106-115.

Tesoriero, R., J.A. Gullard and M. Lozano. 2014. 'Enhancing visitors' experience in art museums using mobile technologies." Inf Syst Front, 16: 303-327.

tom Dieck, M. C., T. Jung and D. tom Dieck. 2016. "Enhancing art gallery visitors' learning experience using wearable augmented reality: generic learning outcomes perspective." Current Issues in Tourism: 1-21. doi.org/10.1080/13683500.2016.1224818

Vavoula, G., M. Sharples, P. Rudman, J. Meek and P. Lonsdale. 2009. "My art space: design and evaluation of support for learning with multimedia phones between classrooms and museums." Computers and Education, 53: 286-299.

Vince, R. 1998. “Behind and beyond Kolb's learning cycle.” Journal of Management Education, 22: 304-319.

Yardley, S., P.W. Teunisse and T. Dornan. 2012. "Experiential learning: Transforming theory into practice." Medical Teacher, 34(2): 161-164.

Yoon, S.A. and J. Wang. 2014. "Making the invisible visible in science museums through augmented reality devices." Tech Trends, 58(1): 49-55.

Yoon, S.A., J. Wang and C. Steinmeier. 2012. "Using augmented reality and knowledgebuilding scaffolds to improve learning in a science museum." International Journal of Computer-Supported Collaborative Learning, 7: 519-541. 